\title{
Arbor
}

\section{Historia de los Servicios de Inteligencia: El Período Predemocrático}

\author{
Francisco Javier Zorzo Ferrer
}

Arbor CLXXX, 709 (Enero 2005), 75-98 pp.

Los Servicios de Inteligencia en la fase que se extiende desde el final de la guerra civil hasta el fallecimiento del General Franco sufrieron, como es lógico, las vicisitudes propias de una organización que estuvo sometida, en un principio, a la situación mundial, derivada del desarrollo de la Segunda Guerra Mundial y a la precariedad de medios, humanos y materiales, fundamentalmente hasta la década de los años 70, que se derivaban de la propia situación nacional.

En sus orígenes estuvieron obligados a mantener una estructura similar a la existente durante la guerra civil , como consecuencia del desarrollo de la guerra en Europa y de la amenaza que representaban los miembros de las fuerzas republicanas que, poco después de finalizar la guerra y regresar a España, intentaron derrocar el nuevo régimen surgido al concluir la contienda.

Los Servicios militares tuvieron claramente definidas desde el principio sus tareas, aunque sus limitaciones de toda indole parece apuntar una justificación a la escasez de éxitos. Policía y Guardia Civil enfocaban sus labores informativas, fundamentalmente, a la persecución del crimen en concreto. Ello no quiere decir que desatendieran totalmente el campo de la inteligencia, pero, por sus peculiares misiones, parece comprensible que sus labores informativas se dirigieran al cumplimiento de sus misiones específicas.

Se puede afirmar, sin temor a error ni a herir susceptibilidades que, ante la subversión latente que hizo su aparición en la Universidad, siguiendo otras corrientes europeas, la necesidad de combatirla dio origen a la creación del incipiente y primer Servicio de Inteligencia de la pos- 
guerra, la Organización Contrasubversiva Nacional (OCN), que, con su evolución y ampliación de tareas a otros ámbitos de la sociedad española, constituyó el germen del Servicio Central de Documentación (SECED), primer servicio de inteligencia con una organización adecuada aparecido en España y que, tras su fusión con la Tercera Sección del Alto Estado Mayor, propició el nacimiento del Centro Superior de Información de la Defensa (CESID), precursor del actual Centro Nacional de Inteligencia.

"Pues si el príncipe esclarecido y el general competente derrotan al enemigo cada vez que pasan a la acción, si sus hazañas se salen fuera de lo común, es gracias a la información previam. Sun Tzu (El Arte de la Guerra).

\section{Generalidades. Los Servicios de Información Militares}

Resulta fácilmente comprensible que durante los primeros años de la posguerra en España, los servicios de información, como se denominaban entonces, tuvieran que mantener una estructura, si no idéntica, sí muy similar a la establecida durante el periodo bélico.

El comienzo de la Segunda Guerra Mundial obligó a mantener una organización militar distinta a la que hubiera sido de desear tras la guerra civil. La existencia de miembros del bando republicano, tanto en el interior como en el exterior de España, con diferente grado de actividad, unos tratando de salvar sus vidas y otros queriendo proseguir sus actividades armadas para combatir, desde sus posibilidades, al gobierno surgido del bando vencedor en la contienda, obligó a que los servicios de información mantuvieran prácticamente sus objetivos, su organización y sus fines.

La no beligerancia de España durante la conflagración mundial no significaba que nuestro país iba a quedar al margen de las actividades de los bandos enfrentados. El apoyo recibido de Alemania e Italia durante el conflicto civil, hacía suponer que los aliados verían a nuestro país como, al menos potencialmente, más próximo al Eje y, por lo tanto, constituía un objetivo informativo de primer orden para ambos bandos. 
Historia de los Servicios de Inteligencia:...

Así pues, el máximo esfuerzo de los diferentes servicios de información en los primeros años de la posguerra estuvo dirigido a contrarrestar las actividades de los enemigos del régimen salido de la guerra española (1936-39). Tanto los internos como los provenientes de allende de nuestras fronteras.

Desde el punto de vista militar los servicios de información que funcionaron durante la guerra civil eran similares en su denominación, servicio de inteligencia militar (SIM), en el bando republicano y servicio de información militar (SIM) en el franquista. Durante la guerra este servicio de información pasó a denominarse Servicio de Información y Policía Militar (SIPM), organizándose, a su vez, un específico Servicios de Información en el Nordeste de España (SIFNE), impulsado por el propio General Mola.

En agosto de 1937, Indalecio Prieto, Ministro de Defensa Nacional, encomendó a Antonio Pedrero García, Jefe de los Servicios Especiales del Ejército del Centro, la reorganización de la inteligencia militar. Esta decisión dio origen del Servicio de Inteligencia Militar del Ejército Republicano, que comenzó a actuar en octubre del mismo año y que pronto consiguió algún éxito importante en el campo de la contrainteligencia.

El Servicio de Información y Policía Militar del Ejército Nacional fue creado el 30 de noviembre de 1937 y sus trabajos fueron dirigidos a la investigación militar en territorio enemigo o en el extranjero, "con separación absoluta de las Segundas Secciones de Estado Mayor, a las cuáles compete la información total de carácter militar», al establecimiento de la seguridad y orden público en la zona de la vanguardia y al contraespionaje en regiones, centros o lugares de interés militar.

Ante la necesidad de coordinar esfuerzos y explotar al máximo la información obtenida, por Decreto de 28 de febrero de 1938, « la organización informativa de orden privado, Servicio de Información de la Frontera Nordeste de España, pasó a formar parte del Servicio de Información y Policía Militar del Estado español (S.I.P.M.)», del que, como ya se ha apuntado nació el Servicio de Información Militar de la posguerra1.

Acabada la guerra, el SIPM se convirtió en un órgano represivo, útil sólo para desenmascarar, perseguir y procesar a los «rojos». En otro sen-

1 L. Canis Matutes «La Organización Informativa y el Agente Secreto», Madrid, [s.d.], 1947, p. 164 .

«El agente de información militar debe poseer la moral más desinteresada, un sentimiento de la verdad inquebrantable, manifestar una defensa decidida por la causa nacional y una devoción ilimitada por la Patria, capaz de los máximos sacrificios. 
tido fue patente el menosprecio de los «combatientes» hacia los que habían participado en la guerra como agentes del SIPM².

Al finalizar la guerra, entre el 28 de marzo y el 18 de mayo de 1939, du rante la «preparación» del desfile de la Victoria, el SIPM, por propia inicia tiva se dedicó " a limpiar la capital de asesinos, cómplices y encubridores".

Como es fácilmente comprensible, tras el traslado a Madrid de la Administración Central, los diferentes Servicios de Información trabajaban con una práctica y total descoordinación, con tensiones y confrontaciones en cuanto a las competencias, principalmente entre los falangistas y los específicos militares.

En 1939, por medio de la Ley de 8 de agosto, se crean los tres Ministerios militares: Tierra, Marina y Aire, que indudablemente comenzaron a organizar sus preceptivas segundas secciones o divisiones, encargadas de las labores de inteligencia propiamente militar.

Por su parte, la ley de 22 de septiembre de 1939 definió la organización del Ministerio del Ejército, asignando a la Secretaría General el «tratamiento de los asuntos reservados en relación con la disciplina militar y de orden público en cuanto afecte al Ejército».

A su vez y por Orden de 11 de noviembre de 1939 (BOE núm. 321) se organiza el Estado Mayor del Ejército, figurando entre las materias de su competencia "obtener, con medios de investigación propios, así como ordenar e interpretar, toda la información precisa para mantener al día el conocimiento de la organización, y de los proyectos técnicos y militares de las Ejércitos extranjeros y sus propósitos y planes de operaciones».

Se organiza en una Secretaría y seis secciones, siendo competencia de la Secretaría, entre los temas propios de la misma, las relaciones con los Estados Mayores de Aire y Marina y con el Alto Estado Mayor.

La Sección Segunda es la de «Información», asignándosela, por la citada Orden, diversos cometidos que en lo referente a la inteligencia se concretan en: Información del extranjero y estudio de la organización de los Ejércitos extranjeros. Será, asimismo, la encargada de los servicios de información documental, testifical y gráfica, de la captación y criptografía y claves ${ }^{3}$.

2 S. Mateo Marcos, 1942, p. 133.

"El Servicio de Información y Campaña" (1942) definía al oficial de Información como trabajador, activo, minucioso, constante y que no ha de dejarse descorazonar por la falta de éxitos inmediatos».

3 BOE. $n^{\circ} 321,1939$, p. 6455. 
Será también responsable de los Planes de información de los distintos planes de campaña y en maniobras, de los cursos de información y del establecimiento de los métodos del Servicio de Información. Controlará, mediante su lectura, la prensa nacional y extranjera y estará encargada de las relaciones con el Ministerio de Asuntos Exteriores en lo que se refiere a las misiones específicas del Estado Mayor del Ejército, así como del establecimiento y mantenimiento de relaciones con los agregados militares extranjeros en España y con los españoles en el extranjero.

La peculiar situación en que vivían los diferentes Servicios se normalizó al promulgarse la ley de 15 de marzo de 1940 (BOE $\mathrm{n}^{\circ} 77$ ) en la que se dispone que los servicios de policía, orden y vigilancia pertenecerán a la Guardia Civil, adscrita a las Fuerzas Armadas.

El Coronel Ungría, antiguo jefe del SIMP, Director General de Seguridad tras finalizar la guerra civil, decidió retirar a la Policía Militar del mantenimiento del orden público, entregar sus ficheros a la Dirección General de Seguridad y reagrupar el SIMP.

El SIMP se dividió en dos secciones: un destacamento contra el SIM republicano, que también se ocupaba de perseguir a los marxistas, y otro, denominado "sección contraguerrillas", formado por los agentes que habían permanecido en Madrid durante la contienda, para liquidar asuntos pendientes de investigación, cuyo primer jefe fue Gutiérrez $\mathrm{Me}$ llado. Tenían su sede en la calle Núñez de Balboa, $n^{\circ}$ 66. Para realizar este trabajo se apoyaron en la documentación localizada en Alcalá de Henares, en la que figuraba "todos los actos de sabotaje, incursiones en la Zona Nacional, golpes de mano y organización completa de los servicios republicanos, con nombres de encubridores, guías y cómplices que permanecían viviendo en la España de la posguerra».

Como consecuencia del asesinato del Comandante de la Guardia Civil, Isaac Gabaldón Irurzun, cuando se dirigía a Talavera de la Reina, el 29 de julio de 1939, y la serie de conflictos internos que se originaron, el Ministro del Ejército, General Valera, ordenó la disolución del SIPM.

Quizá la principal misión del SIM, en aquellos tiempos, era la de llevar a cabo la tarea de preparar y redactar boletines de información que se hacían llegar a los distintos escalones de mando. No tenían ni formato ni periodicidad fija.

Varias veces al día se enviaban al Ministro, al Subsecretario y al Jefe del Estado Mayor del Ejército un breve informe titulado «Noticias recibidas del Servicio de Escucha sobre las operaciones en Europa», junto con 
un «Boletín de Información del Centro de Escuchas», con teletipos de la prensa internacional.

Tres o cuatro veces al mes, se redactaba un «Boletín de Información Secreto", que contenía informes recibidos de los agentes desplegados en el interior o en el extranjero, prestando especial atención al tráfico marítimo de Gibraltar, a la situación de Tánger y Portugal y a las actividades de los nacionalistas marroquíes, incluyendo también noticias de los sabotajes producidos en territorio nacional, declaraciones de políticos españoles y extranjeros, protestas por detenciones y ejecuciones y estados de opinión de los militares.

Con bastante menor frecuencia, el Servicio de Vigilancia Interior de la $2^{a}$ Sección del Estado Mayor del Ejército redactaba una «Hoja Informativa", con comentarios sobre la situación de la sociedad española o sobre las actividades de los exiliados en Francia.

La $2^{\text {a }}$ Sección también recopilaba y archivaba la propaganda contra el Régimen, detectada en unidades militares o enviada a los domicilios particulares de jefes y oficiales.

Como es lógico, también le competía a la $2^{a}$ Sección la investigación de redes de espionaje, en las que con determinada frecuencia se veían implicados los soldados de reemplazo, conducidas por las diferentes embajadas establecidas en Madrid.

Por decreto de 30 de agosto de 1939 se crea, bajo la dependencia directa del Jefe del Estado, el Alto Estado Mayor, y entre sus cometidos figura:

«e) Facilitar al Mando Supremo la información necesaria para la más exacta apreciación del potencial militar y económico de otros países.

El Alto Estado Mayor estaba constituido por un General Jefe, que será miembro y Secretario de la Junta de Defensa Nacional, una Secretaría y Tres Secciones: $1^{\mathrm{a}}$.- Militar, $2^{\mathrm{a}}$.- Económica y $3^{\mathrm{a}}$.- Información.

La Tercera Sección tenía como misión general la específica de Información, que aparece entre los cometidos fundamentales y que, por Orden Reservada de 5 de febrero de 1944, recibió la misión de «enfrentarse, dentro de España, a los complejos Servicios de Espionaje extranjeros» y «coordinar la acción de los diversos organismos encargados de reprimirlos», pero debido a la amplitud de dichos cometidos se presentaron algunos conflictos de competencia con el Ministerio de la Gobernación, por lo que a finales de 1945, y de nuevo por una Orden Reservada, se precisaron con más detalle sus atribuciones:

«Será de la incumbencia del Alto Estado Mayor cuanto se refiere al es- 
pionaje y contraespionaje de carácter militar, dentro y fuera del país. Incumbe a cada Ministerio, la información de carácter general, de acuerdo con sus necesidades. Corresponde al Ministerio de la Gobernación (Dirección General de Seguridad) cuanto se refiere a la seguridad interior del país. Se entiende por seguridad, el conocimiento anticipado y la destrucción o anulación de cuantas actividades se dirijan a perturbar el orden público o poner en peligro la vida del Estado».

La Tercera Sección del Alto Estado Mayor se reorganizó en 1945, constituyéndose cinco áreas: $1^{\mathrm{a}}$, Información sobre países anglosajones; $2^{\mathrm{a}}$, Europa y Rusia; $3^{\mathrm{a}}$, Países africanos; $4^{\mathrm{a}}$, Cifra y escuchas y $5^{\mathrm{a}}$, Contraespionaje.

Las tareas de contraespionaje correspondía a la eufemísticamente denominada "Comisión de Estadística», ubicada en unas dependencias encubiertas situadas en la calle Francisco de Rozas $n^{\circ} 4$.

El Servicio de Información del Alto Estado Mayor comenzó sus trabajos con gran precariedad de medios. Muchas de las personas integradas en el mismo estaban pluriempleados, como sucedía a muchos de sus compañeros de profesión, consecuencia de lo escaso de los haberes que percibían, por lo que su eficacia, durante muchos años, fue más bien escasa, más acusada en algunos campos que en otros, como podía ser el de la contrainteligencia.

En abril de 1946, en el marco de la reorganización administrativa iniciada al finalizar la II Guerra Mundial se introdujeron algunas modificaciones en la estructura del Alto Estado Mayor, entre las cuales se incluyó que la Comisión de Estadística pasara a denominarse Comisión de Estudios, y se de dicara al control y manejo de los agentes desplegados en el extranjero.

Los agentes españoles en el extranjero solían tener su sede en la Embajada de España en el país donde se encontraban, con la misión de entrar en contacto con los órganos de inteligencia del país en cuestión, para obtener la información que pudiera ser de interés para nuestro paíst.

4 F. Puell de la Villa. Gutiérrez Mellado. Un militar del Siglo XX, Madrid, Biblioteca Nueva, 1997.

«El militar que pasaba excesivo tiempo destinado en los Servicios de Información, llegaba a sufrir un proceso de deformación profesional, que lo inhabilitaba para desenvolverse con naturalidad en el mundo castrense. (Gutiérrez Mellado)».

M. GutiérRez Mellado. Un soldado de España. Conversaciones con Jesús Picatoste, Barcelona, Arges Vergara, 1983, p. 116.

«Cuando se permanece demasiado tiempo en el servicio de información, sin que el interesado se percate de ello, va dejando de ser un oficial para convertirse en un mero in formador.(Gutiérrez Mellado)». 
El General Gutiérrez Mellado intervino directamente en la instalación y seguimiento de las bases establecidas en Bélgica, Francia, Portugal y Suiza.

La razón de establecer estas bases respondió a determinados acontecimientos concretos, como pudieron ser:

- El establecimiento en París del Gobierno republicano en el exilio.

- La llegada del conde de Barcelona a Estoril (Portugal).

- Los contactos que se mantenían en Bélgica y Suiza con la URSS.

A partir de 1955, tras el reconocimiento de las Estados Unidos y la existencia de bases americanas en España, el objetivo soviético comienza a tener una especial dimensión, lo que exigía una preparación más profunda en esa dirección. Oficiales españoles se desplazan a Estados Unidos e Inglaterra para recibir formación específica en el campo de la información y se comienza a desplegar agentes españoles en el extranjero, marchando, durante bastante tiempo, de la mano de la CIA.

En 1962 se produce una nueva reorganización de la Tercera Sección del Alto Estado Mayor, dedicando un especial énfasis en las tareas de contraespionaje, control de actividades comunistas, tanto en el interior como con respecto a las posibles relaciones con Rusia y Cuba, de las organizaciones anti-régimen, evaluación del ambiente socio-laboral y del campo universitario, aunque hay que significar que sus trabajos no pudieron contar con el suficiente personal y la necesaria dedicación, por lo que no se obtuvieron los frutos deseados.

Cuatro años después, en 1966, se crea dentro del mismo Servicio, la Sección Operativa de Misiones Especiales, para llevar a cabo determinadas acciones operativas. En 1972 centró sus trabajos en el campo del contraespionaje.

Una vez constituido el SECED las tareas asignadas al AEM estuvieron relacionadas con actividades de Inteligencia exterior, Contrainteligencia y Espionaje del Espacio Radioeléctrico, contando, además, con un Grupo Operativo.

\section{La Organización Contrasubversiva Nacional (OCN) y el Servicio Central de Documentación (SECED)}

No cabe ninguna duda que, en los últimos años de la posguerra, el peso de las labores de inteligencia en España han corrido a cargo, en primer lugar, de la Organización Contrasubversiva Nacional (OCN) y, posteriormente, del Servicio Central de Documentación (SECED), que tras fusionarse con el Servicio Exterior del Alto Estado Mayor (AEM), origi- 
naría el Centro Superior de Información de la Defensa (CESID), antecedente del actual Centro Nacional de Inteligencia (CNI), y que será tratado por otros articulistas.

El nacimiento del Servicio de Inteligencia español está circunscrito prácticamente a una sola persona. En concreto al entonces Comandante José Ignacio San Martín.

En su obra autobiográfica "Servicio Especial. A las órdenes de Carrero Blanco», el Coronel San Martín confiesa sus inclinaciones juveniles por los asuntos referidos al espionaje y a la criptografía, por lo que para realizar el curso de criptografía convocado en 1947, se trasladó a Madrid, desde Marruecos, donde se encontraba destinado.

Su agregación a la Comisión de Estudios del Alto Estado Mayor, para realizar tareas de descriptación de los telegramas captados en Marruecos, le abrió las puertas para, posteriormente, ser enviado a París, como Vicecónsul y representante del Alto Estado Mayor ante los servicios de información de aquel país.

Instalado en París, estableció relaciones con el SDEC francés, rama de espionaje, y con el Ministerio del Interior: directas, con la Dirección de Información General e, indirectas, con la Dirección de Vigilancia del Territorio (DST), servicio de contraespionaje francés, que tenía capacidad de detener a los presuntos espías al servicio de potencias extranjeras.

En aquellos tiempos una de las tareas más relevantes encargadas a los representantes del AEM fuera de España, era el control de las actividades de los miembros del antiguo gobierno de la República española.

Tras su regreso a España, en agosto de 1966 se reincorporó al AEM. En concreto, al Negociado de Interior de la $3^{\text {a }}$ Sección, donde se le asignó la Jefatura del grupo sindical.

El 27 de septiembre de 1968, el General Jefe del AEM recibió una petición de apoyo técnico, desde el Ministerio de Educación , para tratar de evitar que se incrementara la subversión estudiantil hasta el extremo de que se repitiera en España una situación similar a la del «mayo francés». Así nació la Organización Contrasubversiva Nacional, dedicada, al principio, en exclusividad al mundo universitario ${ }^{5}$.

\footnotetext{
5 José Ignacio SAN MARTín, Servicio Especial. A las órdenes de Carrero Blanco (De Castellana a El Aaiun), Barcelona, Planeta, 1983, p. 21.

Instrucciones recibidas. Misiones y condicionantes:

$1^{\mathrm{a}}$. Asesorar al Ministro en materia informativa, actuando como su Estado Mayor en dicho campo.

$2^{a}$. Coordinar los elementos dependientes del Ministerio que tuvieran funciones análogas (por ejemplo bedeles procedentes del Ejército y de la Guardia Civil).
} 
El 30 de noviembre de ese año, el Comandante San Martín fue encargado de la tarea. Nace, en la realidad, el Servicio de Inteligencia español por antonomasia. Las instrucciones recibidas fueron de asesoramiento y coordinación, sin implicar en absoluto al Alto Estado Mayor, siendo sus primeras actuaciones las dirigidas a la formación y dirección de grupos de acción y, en segundo lugar, al fomento de movimientos «adictos» y a los trabajos de acción psicológica, constituyéndose en diciembre de ese mismo año el «Gabinete de Enlace del Ministerio de Educación y Ciencia», estableciéndose a continuación un plan de enlaces con otros organismos y concediéndose autorización para establecer contactos con la Dirección General de Seguridad, lo que resultó provechoso y sirvió para aclarar competencias.

La primera actividad que se llevó a cabo fue poner en marcha el denominado «Plan Canadó», de acción psicológica y contraactivismo, lo que obligó a establecer contactos, cada vez más frecuentes, con las fuerzas activas progubernamentales en aquellos momentos: Guardia de Franco, Oficina de Información de Asociaciones, Delegaciones del Movimiento, etc., con el inconveniente que ello representaba ante las múltiples indiscreciones que se producían ${ }^{6}$.

Los comienzos no fueron nada fáciles. El propio Ministro de Educación parecía arrepentido al conocer las dimensiones del problema que se trataba de resolver, pese al apoyo manifiesto del propio Vicepresidente del Gobierno, el Almirante Carrero Blanco.

Con intención de poder enfrentarse con el problema de la subversión, de manera que fuera posible su derrota, el propio San Martín propuso la modificación de la Orden Reservada de 20 de diciembre, en la que se es tablecían las competencias de los diferentes servicios de información, toda

$3^{\text {a }}$. No implicar en absoluto al AEM.

$4^{\mathrm{a}}$. Obtener información por medio de la captación de informadores y de la infiltración de agentes propios.

$5^{\mathrm{a}}$. Ubicación ajena a las instalaciones del Ministerio.

$6^{a}$. Apoyo documental del Negociado de Interior del AEM.

$7^{\mathrm{a}}$. Relaciones con el AEM a través del Jefe de Operaciones de la $3^{\mathrm{a}}$ Sección.

$8^{a}$. El Plan de Acción tenía que ser aprobado por el Jefe del Negociado de Interior de la $3^{\text {a }}$ Sección del AEM.

6 Op. cit., p. 15.

«La constitución de un servicio especial de información es un proceso lento que tropieza con muchas dificultades, entre ellas las derivadas de la existencia de otros servicios similares». 
vez que, desde el punto de vista de la incipiente OCN, la subversión no debería tratarse como un problema exclusivamente técnico, sino que era necesario que fuera considerado como un problema político, general y permanente.

Pronto se sintió la necesidad de que la reducida organización establecida exclusivamente en Madrid, extendiera su ámbito de actuación a provincias, por lo que estableció la primera Delegación en Barcelona, contando lógicamente con el apoyo del Sector Cataluña del AEM.

Para hacerse una idea de lo precario de la plantilla al inicio de las actividades del que posteriormente sería el Servicio de Inteligencia español, tras dos años de funcionamiento, la Organización Contrasubversiva Nacional contaba con 4 jefes y oficiales de los tres ejércitos, la mayoría a plena dedicación.

Según su jefe, lo que la OCN pretendía era contener, y a ser posible, reducir el proceso subversivo; tratar de arrebatar banderas reivindicativas a la subversión; intentar eliminar o reducir las lacras existentes en la sociedad y en la Administración; abrir cauces de participación y contribuir a una evolución política.

En concreto, la misión de la OCN consistía en facilitar información abierta y oculta sobre los movimientos subversivos, realizar acciones de contrapropaganda y llevar a cabo una acción psicológica positiva, dirigida al fomento de movimientos adictos, a la formación ideológica y a la orientación de la opinión.

Desde el principio se estableció que el trabajo del naciente Servicio no iba, en ninguna medida, a duplicar la labor de la Policía Armada o de la Bri gada Político-Social, que tenían claramente definidas sus competencias.

El trabajo de la OCN debía ir dirigido a contrarrestar y anular, por todos los medios, las actividades de quienes pretendían subvertir el régimen. Querían apoyar a los estudiantes menos ideologizados, frente a los, entonces, conocidos como "subversivos", "extremistas", "revolucionarios", «comunistas», etc.

La OCN, para poder participar activamente en la Universidad, sentía la necesidad de contar con una asociación de estudiantes para hacer frente así a los grupos de ideología izquierdista. Los primeros con los que empezaron a trabajar fueron los Guerrilleros de Cristo Rey, que lideraba Mariano Sánchez Covisa, pero como consecuencia de la violencia con la que actuaban, les hacían incontrolables, por lo que se decidió en el seno de la OCN crear una asociación propia.

Tras seleccionar unos cuantos estudiantes afines, se constituyó la Asociación Nacional de Universitarios Españoles (ANUE), siglas que pronto empezaron a competir con las más conocidas en los ámbitos político-universitarios: las del PCE, FLP, etc. Sus estatutos fueron aproba- 
dos por los Ministros de Educación y Secretario General del Movimiento y publicados en abril de $1969^{7}$.

Como otra muestra más de la precariedad con la que trabajaba el Servicio de Información español, en sus comienzos, se puede señalar que, para iniciar sus actividades, recibió en 1968 un préstamo del AEM de 200.000 pesetas. Al siguiente año se constituyó un fondo, primero en el Ministerio de la Gobernación y posteriormente en la Secretaría General del Movimiento, que fue sólo de 10 millones de pesetas, pese a que ya el Servicio se encontraba implantado en toda España. En 1970, el presupuesto se amplió a 15 millones de pesetas, sin incluir los sueldos del personal, ascendiendo en 1971 a 24 millones de pesetas y a 60 millones en 1973.

Todos estos aspectos permiten comprender fácilmente que, en los primeros años, la Organización actuaba con un cierto grado de inestabilidad, consecuencia de las influencias y relaciones políticas y los aspectos financieros, junto con las dificultades de incorporación de personal, las incomprensiones de muchos militares y la dependencia funcional, que a juicio de su Director en aquella época, no era la más adecuada, pues siempre pretendió el Coronel San Martín que su dependencia fuera siempre al más alto nivel.

Otro de los elementos con los que tuvo que, en alguna medida, luchar el Servicio fue con las indiscreciones, no ya las no intencionadas, ocasionadas por aquellos políticos que no tenían conciencia real de su responsabilidad, sino de las que se producían originadas por los recelos de determinados organismos o servicios que se relacionaban con la OCN.

$\mathrm{Al}$ principio se actuó aceleradamente, por órdenes superiores, tratando de paliar la ventaja que había adquirido el «adversario», durante más de seis años, utilizando técnicas similares a las que pretendía emplear el Servicio.

Si las actividades se hubieran limitado al aspecto informativo, la seguridad habría sido total, pero la necesidad de atender varios frentes que, en principio y a juicio de los componentes de la OCN, eran los más

\footnotetext{
7 Op. cit., p. 31.

El pensamiento del Servicio sobre el asociacionismo estudiantil quedó reflejado en la «Memoria de Actividades en el periodo comprendido entre el 27 de septiembre de 1968 y el 31 de marzo de 1969" que presentó la OCN: "De poco servirán las medidas de desarticulación de los grupos hostiles, ni la creación de grupos antagónicos, si no se gana la opinión de las organizaciones estudiantiles adictas o neutrales, que contrarresten la acción de los subversivos" (1969).
} 
importantes, les obligó a proliferar los contactos oficiales, generalmente de alto nivel, lo que originó gran número de indiscreciones, como ya queda dicho.

Por otra parte, el Servicio presentaba, con distintas vinculaciones, la particularidad de ser, por un lado, clandestino, salvo un núcleo de cabeza reducido y, por otro, de estar integrado por un grupo de jefes y oficiales de las fuerzas armadas, en situaciones diversas, sin que ésto pasara inadvertido para un cierto número de autoridades y de otros militares, en quienes, precisamente por las condiciones y procedimientos por los que se producían las agregaciones y comisiones de servicio, despertaban aún más la curiosidad 8 .

Uno de los principales medios que facilitó enormemente las labores de la OCN lo constituyó su fondo documental, su archivo, que fue construido con la cooperación de la Dirección General de Seguridad y de la Dirección General de Política Interior. Pese a ser de explotación manual, puesto que en aquellos tiempos la informática no estaba excesivamente desarrollada en España, constituyó un magnífico soporte para sus estudios y trabajos.

La importancia que desde el principio se dio a la documentación quedó reflejada en la redacción de unas "Normas Generales de Documentación», en las que se analizaba con todo detalle las características y forma de explotar la documentación que custodiaba el Servicio.

Como complemento de lo anterior se constituyó, asimismo, un «Gabinete de Lectura», que analizaba gran número de publicaciones de todo tipo, obteniendo de esta tarea informaciones muy provechosas.

Para obtener información directa se contó con un importante número de colaboradores de distintos tipos, que eran «señalados» por personas de confianza y que conocían el ámbito donde debía desenvolverse el Servicio.

Pese a todo es fácilmente comprensible, hubo serias dificultades para captar colaboradores, fundamentalmente por la sensación que producía en los posibles candidatos de que fueran acusados de «chivatos», junto

\footnotetext{
8 Op. cit., p. 40.

Todos los servicios especiales dedicados a actuaciones encubiertas tienen que cumplir sus misiones conciliando la seguridad con la eficacia. La naturaleza y la urgencia de la misión suele condicionar la seguridad. (Al principio de la OCN hubo que sacrificar, en ocasiones, la seguridad a la eficacia).
} 
con el riesgo que presentaba el tenerse que infiltrar en alguna de las organizaciones controladas.

El primer grupo de colaboradores con los que contó la OCN estuvo constituido por los bedeles de las Facultades, muchos de ellos antiguos militares o guardias civiles retirados, pero pronto fueron detectados, por lo que su eficacia fue muy reducida.

Para conseguir orientar el trabajo de los colaboradores, potenciales o efectivos, se realizaban cursos de formación, que a la larga permitía la captación de candidatos que, a veces, al no estar significados, sus frutos fueron bastante positivos. A finales de 1970 la OCN contaba con $380 \mathrm{co}$ laboradores de ambos sexos, en toda España.

Para cualquier servicio de información incipiente, no cabe duda que la coordinación de esfuerzos de toda índole constituye un significado caballo de batalla. En el caso de la OCN el problema apareció enseguida, aunque por la insistencia de sus dirigentes se consiguió que, en los cinco meses comprendidos entre octubre de 1969 y marzo de 1970, se reunieran casi todas las semanas, bajo la presidencia del Almirante Carrero, los ministros de Educación y Ciencia, Gobernación, Ejército, Justicia y Secretario General del Movimiento.

A principios de 1971 y considerando que la defensa institucional debía ampliarse a todos los frentes, y siguiendo una iniciativa del propio Almirante Carrero, se redactaron unas «Bases de reestructuración del Servicio», apoyándose en criterios derivados de la experiencia adquirida hasta la fecha.

Se fijaron nuevos niveles de responsabilidad, se creó un órgano de coordinación, se estableció que todos los miembros del Servicio estuvieran adscritos a "plena dedicación" y se ampliaron las actividades al mundo sindical y al sector religioso-intelectual.

En el sector sindical, apoyándose en muchas ocasiones en las estructuras del Sindicato Vertical, se desarrolló un plan de acción psicológica especializado, se organizó un servicio de información específico y se llevo a cabo un plan de revitalización de centros sindicales en las barriadas, en coordinación con las redes de teleclubes urbanos del Ministerio de Información y Turismo.

En el sector religioso-intelectual, que en sus comienzos se ocupaba esencialmente de temas políticos, se dedicó a la explotación de informes y estudios relacionados con esa actividad, se organizó una red de periodistas que transmitiera las ideas propuestas por el Servicio, se apoyó, en la medida de lo posible, a las publicaciones proclives y se incrementó el 
número de socios del Ateneo, para poder extender allí la influencia de la $\mathrm{OCN}^{9}$.

A finales de 1971 se hizo un nuevo planteamiento acerca de la estructura del Servicio, que iba a consistir en la creación de un Centro de Información y Documentación (CIDOC) que, bajo la dependencia directa de la Presidencia del Gobierno, fuera la ventana abierta de la Organización y que sirviera para dar carta de naturaleza al Servicio, como había sucedido con los más conocidos servicios de información extranjeros ( la CIA en Estado Unidos; el KGB en la URSS, el MI - 5 en el Reino Unido; el SDEC en Francia y el Servicio Federal de Información o Servicio de Defensa de la Constitución en la República Federal Alemana).

Ante esta propuesta el Almirante Carrero Blanco decidió y despachó con el Jefe del Estado, el 22 de enero de 1972, crear una Dirección General, en el seno de la Presidencia del Gobierno, que cumpliese misiones de información abiertas y encubriese las actividades secretas, completando todo ello con enlaces eficaces, tanto en el ámbito sectorial como en el geográfico.

A principios de febrero de ese año, el Tcol San Martín le presentó una nueva propuesta, en la que la estructura de la parte visible de la organización quedaría configurada en una jefatura y una secretaría general, además de las siguientes unidades administrativas: administración, estudios e informes y coordinación, con delegaciones regionales y enlaces en diversos departamentos ministeriales. Además subsistirían los sectores de Acción Psicológica, Sindical y Religioso-intelectual, junto a los Departamentos de Información y de Operaciones. El personal militar estaría destinado en el AEM.

Por Decreto 511/1972 de 3 de marzo se dio nueva redacción al apartado 2 del artículo $2^{\circ}$ del Decreto 245/1968, de 15 de febrero, sobre reorganización de la Presidencia del Gobierno, creándose el Servicio Central de Documentación (SECED) y estableciendo su dependencia directa del Ministro Subsecretario de la Presidencia del Gobierno.

Posteriormente por Orden de 16 de marzo de 1972 (BOE núm 68) se' estructura el Servicio Central de Documentación de la Presidencia del Gobierno y se establece que será el órgano encargado de realizar y difundir informes y estudios, prestar asistencia técnica y coordinar la do-

\footnotetext{
9 Op. cit., p. 36.

«Las técnicas en el campo de la información, si no van acompañadas de medidas políticas adecuadas, acaban por fracasar de una manera global, pese a que proporcionen éxitos aislados y esporádicos».
} 
cumentación en relación con la protección de materias clasificadas, así como cuantas funciones asesoras le encomiende expresamente el Ministro Subsecretario.

Se estructuraba en las siguientes unidades:

- Sección de Régimen Interior, que tendría como funciones, además de la gestión administrativa del Servicio, la coordinación de los Servicios de protección de materias clasificadas de los distintos Departamentos ministeriales civiles.

- Sección de Estudios e Informes, que se encargaría de la adquisición, estudio y explotación de cuanta documentación fuera de interés para la Presidencia del Gobierno.

- Sección de Coordinación y Enlace, que tendría como funciones la relación permanente con las Delegaciones Regionales y las Oficinas de enlace de los departamentos ministeriales civiles, para la difusión y coordinación de la documentación.

Asimismo, se establecía que podían crearse Delegaciones Regionales del Servicio Central de Documentación, «con el ámbito territorial que expresamente se determine, para el ejercicio de las funciones encomendadas al mismo en una circunscripción determinadoor, así como la posibilidad de constituir Oficinas de enlace en los distintos Departamentos ministeriales civiles.

A finales de 1973, la organización periférica contaba con doce delegaciones regionales, y siete subdelegaciones provinciales, adscritas a sus respectivas cabeceras regionales.

Con el apoyo de las unidades administrativas actuaba el grueso del Servicio, la parte oculta del mismo. En total, el SECED estaba integrado ese año por doscientas personas, incluido el personal auxiliar, unos cinco mil colaboradores, de ellos unos dos mil directos y, a su vez, de éstos, unos quinientos informadores.

La estructura de esta organización se apoyaba en dos grandes Divisiones: la de Información y la de Operaciones. Los campos de actividad, como ya se ha citado anteriormente, continuaban siendo los sectores educativo, laboral y religioso-intelectual. Además contaba con el Gabinete de Acción Psicológica, el Departamento de Asuntos Especiales y la Secretaría General, que, en realidad trabajaba como un auténtico estado mayor del Servicio, constituyendo, simultáneamente, el órgano receptor de la información abierta. 
La División de Información tenía como misiones:

- El tratamiento de la información recibida de otros servicios para su explotación por el propio Servicio y otros organismos.

- La obtención de información complementaria o adquisición de información de origen propio para su tratamiento y explotación con análogos fines. Estaba organizada en:

- Departamento de documentación, estudios e informes, encargado del tratamiento de la información.

- Departamento de investigación, para la obtención de la información propia.

- Grupo de apoyo técnico, que se ocupaba del perfeccionamiento del material técnico para la obtención de información.

Entre los trabajos que realizaba dicha División destacaban:

- Un fichero completísimo de personalidades del régimen y de la oposición, así como de los que pudieran denominarse «grupos de presión", conocido con el nombre de JANO.

- El estudio de todas las organizaciones y grupos clandestinos.

- Ficheros sectoriales.

- El montaje de redes informativas.

- La realización de operaciones especiales de investigación con medios y técnicas modernos.

- La investigación sobre medios técnicos y la adquisición del material más adecuado a los servicios a llevar a cabo.

La División de Operaciones era el «cliente» de la División de Información. Sus misiones eran:

- Difusión de información y asesoramiento técnico a organismos estatales.

- Formación de movimientos adictos.

- Acción psicológica propiamente dicha, a través de la orientación de la opinión pública y el fomento del asociacionismo, en íntima relación con el Gabinete de Acción Psicológica.

Su organización era la siguiente:

El Sector Educativo, como ya queda dicho, fue el pionero del Servicio $\mathrm{y}$, consecuentemente, tenía una gran experiencia, pero tropezaba con 
graves dificultades, al no existir estructura propia donde apoyarse, por el "vacío» producido con la desaparición del SEU.

Tenía que colaborar a frenar o encauzar la rebelión estudiantil y contrarrestar la posible acción de los «deformadores de la juventud estudiantil»; luchar contra la falta de ejemplaridad de la sociedad y denunciar los fallos político-administrativos en el ámbito de la educación. En el campo de la información dependía de la que le proporcionaba la División de Información y de la que obtenía de sus colaboradores.

En materia de asesoramiento recomendaba las medidas que deberían adoptarse ante situaciones conflictivas y en el campo de la formación impartía cursos dirigidos a la captación de grupos positivos.

En lo relativo a la acción psicológica, fomentaba el asociacionismo y la representación estudiantil, combatiendo la propaganda hostil.

El Sector Laboral prestaba asesoramiento, tanto al Ministerio de Trabajo, como a la Organización Sindical y les proporcionaba información tendente a evitar o paliar situaciones conflictivas.

Realizaba cursos para dirigentes sindicales, mandos intermedios y vocales juveniles de jurados de empresa. ( En nueve meses, en 1973, se realizaron 50 cursillos, en 16 provincias, asistiendo a los mismos unas 2.000 personas).

Inició el montaje de despachos jurídico-laborales, para hacer frente a los incipientes despachos laboralistas organizados por el PCE.

El Sector Religioso-Intelectual estaba orientado, fundamentalmente, a la Iglesia y a algunos Colegios profesionales, tratando más marginalmente los medios artísticos e intelectuales.

Facilitaba información y asesoraba a los organismos interesados, difundía documentos destinados a combatir corrientes adversas y coordinaba la labor de grupos y publicaciones favorables.

El Gabinete de Acción Psicológica (GAP) organizaba e impartía cursos de formación y especialización para los medios del Servicio. Constituía el centro de doctrina del Servicio, coordinando la operación denominada "Criterio», de formación permanente.

Colaboraba en conferencias a entidades públicas, ejercía el control de la propaganda propia y analizaba la adversa, para reorientar la primera, colaborando además en la selección de personal y ocupándose de las colaboraciones en los diferentes m.c.s.

La Secretaría General se ocupaba de los temas de organización, personal, infraestructura logística y habilitación, absorbiendo la parte abierta del Servicio.

El Departamento de Asuntos Especiales se ocupaba de casos y operaciones que no correspondían a ningún sector en concreto o de aquellos asuntos que asumía, para su dirección, la Jefatura del Servicio. 
Historia de los Servicios de Inteligencia:...

Se mantenías relaciones múltiples, con diferentes actitudes por parte de los difrentes interlocutores y resultados no siempre positivos para el Servicio. En concreto existían relaciones establecidas con el Ministerio de la Gobernación, Ministerio de Información y Turismo, Ministerio de Educación y Ciencia, Organización Sindical, Ministerio de Trabajo, Secretaría General del Movimiento a través de la Delegación Nacional de la Juventud y de la Delegación Nacional de la Sección Femenina. La excepción la constituyó el Ministerio de Asuntos Exteriores, presumiblemente porque las labores de información en el exterior correspondían al Alto Estado Mayor.

La coordinación entre servicios ha constituido siempre, y no solamente en España, un campo de batalla en el que había que hacer frente a múltiples situaciones.

En este sentido y desde mediados de marzo de 1973, el Director del Servicio entró en contacto con el TGral. Gutiérrez Mellado para tratar de conseguir un entendimiento definitivo con el Alto Estado Mayor, con vistas a una mayor conexión con los correspondientes Servicios de las Fuerzas Armadas.

A pesar de todo, en las relaciones con el Ejército y en especial con con Servicio de Información, se tuvieron algunos tropiezos. Muchas de las dificultades que se presentaron eran, en parte, responsabilidad del propio Servicio.

El 23 de mayo de 1973, el Almirante Carrero Blanco expresó al Director del SECED su preferencia de que el Servicio dependiera directamente de él y que el Alto Estado Mayor se dedicara a la información militar en su doble vertiente: información y contrainformación.

Los Servicios militares específicos, más los de las Direcciones Generales de Seguridad y de la Guardia Civil, deberían ser coordinados por la Presidencia, a través de las Secretarías de Juntas y Comisiones de trabajo.

El 26 de septiembre de 1973, quedó configurada la Comisión Nacional de Coordinación de la Información para la Seguridad del Estado, presidida por el Presidente del Gobierno e integrada por el Vicepresidente del Gobierno, los Ministros de la Gobernación, Información y Turismo y Subsecretario de la Presidencia y el Tte. Gral. Jefe del Alto Estado Mayor, con la presencia de los ministros militares cuando era necesario

El trabajo llevado a cabo personalmente por el Director del Servicio personalmente con el Tte. Gral. Gutiérrez Mellado obtuvo pronto frutos en este campo, consiguiendo una más que aceptable coordinación entre el AEM y el SECED. 
Como prueba de ello, el sistema de archivos utilizados por el SECED se apoyaba en al banco de datos que almacenaba el ordenador IBM que disponía el AEM, que siendo uno de los primeros utilizados en España, tenía memoria suficiente para una rápida explotación de la información almacenaba.

El 20 de diciembre de 1973 es asesinado Carrero Blanco. Este hecho tuvo una gran influencia en el desarrollo posterior y en la credibilidad del SECED, pues «No habian sido capaces de detectar, de ninguna manera, la posibilidad de que fuera a cometerse el atentador.

La acción inmediata del SECED fue contactar con políticos y líderes sindicales, incluso clandestinos, para transmitirles un mensaje de tranquilidad y confianza en el sentido de que no se iba a llevar ninguna acción de persecución y represalia («Operación Promesa»), manteniendo encuentros clandestinos y semiclandestinos, con los más significados representantes políticos y sindicales.

El nombramiento de Arias Navarro como Presidente del Gobierno trajo consigo el cese de San Martín como Director del SECED, siendo sustituido por Juan Valverde, Comandante de Infantería y amigo personal de Arias. Fraga designó a San Martín como Director General de Tráfico.

Este nombramiento, el de Arias Navarro, produjo cierta frustración en el SECED. Había sido el Ministro de la Gobernación, responsable de la Policía y también había fracasado en la prevención del atentado contra Carrero Blanco.

Valverde consiguió potenciar espectacularmente el Servicio de Inteligencia. Su amistad personal con Arias Navarro no estaba lejos de ese logro. El SECED dobló, en muy poco tiempo, el personal que lo integraba. De 60 miembros pasó a tener 120 .

En 1974 se produjo la adscripción de Andrés Casinello al SECED. Comandante de Infantería, que ya había trabajado en los comienzos de la OCN (sector laboral) y que había tenido destinos y realizado cursos en Alemania y Estados Unidos. Era el autor de un trabajo sobre los Servicios de Información, para el que se había basado fundamentalmente en su propia experiencia. Se comentó que para entrar de nuevo a trabajar en el SECED, había exigido a Valverde que tenía que aceptar como base del funcionamiento del nuevo Servicio, las ideas expresadas en su trabajo "Ante el cambio», que se refería a la situación que se avecinaba como consecuencia del estado de salud del Jefe del Estado y a los previsibles cambios que podían originar tras su fallecimiento. Se incorporó al finalizar el verano de 1974, como Jefe de la División de Operaciones. 
Historia de los Servicios de Inteligencia:...

Valverde aceptó la propuesta de Casinello, y en diciembre de ese año el citado trabajo fue presentado a todos los oficiales del Servicio como "doctrina de obligado cumplimiento». Nacía un nuevo SECED, primer paso para alcanzar una nueva y mas completa organización, el CESID.

\section{El Servicio de Información de la Guardia Civil}

Desde la fundación de la Guardia Civil en 1844 hasta después de finalizada la Guerra Civil no figura en sus reglamentos y normas de actuación, ninguna cita con carácter oficial que haga alusión al Servicio de Información.

Sin embargo es fácilmente comprensible que durante tan dilatado periodo, la Guardia Civil tuvo que realizar tareas de información para el cumplimiento de sus variadas misiones, especialmente las dirigidas a la lucha contra la delincuencia, persecución del contrabando, lucha contra el bandolerismo y previsión de movimientos subversivos.

La Ley de 15 de marzo de 1940 (BOE. Núm. 77) por la que se reorganiza el Cuerpo de la Guardia Civil, en su Artículo quinto, establece entre sus cometido, junto con " la vigilancia y guardia de los campos, pueblos, factorías, centros industriales y mineros, costas y fronteras, la persecución del contrabando y el fraude y la previsión y represión de cualquier movimiento subversivo, $y$, en todo momento y lugar, la persecución de delincuentes».

La Orden de Ministerio del Ejército de 8 de abril de 1940, referente a la organización provisional del la Dirección General de la Guardia Civil, como consecuencia de su pertenencia al Ejército de Tierra, al crear su Estado Mayor, figura por primera vez, de forma oficial, cometidos de información, asignados, como es lógico a su Segunda Sección, pues entre ellos aparece como misión la información e investigación, junto a su responsabilidad sobre ficheros, claves, dactiloscopia e identificación y el enlace con los Servicios de Información de otros Organismos.

La Circular del Cuerpo de 24 de febrero de 1941 y la Orden reservada del 1 de abril de ese mismo año, que completaba la anterior, constituyen las primeras instrucciones para organizar el funcionamiento del Servicio de Información de la Guardia Civil.

Se determina la información que había de remitirse periódicamente por las Oficinas de Información creadas en los Tercios y las Comandancias y figuran por primera vez los diferentes conceptos informativos a que 
atiende el Servicio de Información de la Guardia Civil (SIGC): De carácter militar, de carácter político-social y de carácter privativo de la Guardia Civil, apuntando, sin concretar, las relaciones que habría que mantener con los órganos informativos de los Ejércitos y de la Policía.

En esta fase de creación del Servicio se fijó también su plantilla. En abril de 1941, el Servicio de Información de la Guardia Civil estaba constituido por 52 oficiales, 52 suboficiales, 25 cabos y 230 guardias. Pronto se sintió la necesidad de que las jefaturas del mismo en las diversas unidades fuera ostentada por Comandantes, lo que tiene lugar tras su publicación en la Orden General del Cuerpo número 40, de 21 de noviembre de 1941.

A propuesta de la Segunda Sección de Estado Mayor se crea, con fecha de 21 de noviembre de 1945, el «Grupo de Información e Investigación» de la Dirección General, quedando afecto a la citada $2^{\text {a }}$ Sección, contando solamente con una plantilla de 15 hombres, pero dependiendo directamente del Director General de la Guardia Civil, a través de su Jefe de Estado Mayor, tras cuya reorganización publicada en la Orden General núm. 13, de 11 de marzo de 1959, pasó a denominarse «Grupo de Servicios Especiales» y cuya misión, junto a la específicamente informativa, se extendió a las tareas fiscales que se creyeran convenientes, constituyendo el embrión de la posterior «Unidad de Servicios Especiales».

La importancia que la Guardia Civil ha concedido siempre a la información puede quedar patentizada en que, 29 años después, la plantilla de personal dedicado a tareas informativas se cuadruplicó, pasando de los 369 iniciales a 1.261, contando ya con 91 Comandantes.

No cabe duda que en el periodo de la posguerra comprendido entre los años 1943 y 1952, el Servicio de Información cobró una especial relevancia, por su dedicación, con carácter preferencial, a la lucha contra el «bandolerismo", situación a la que derivaron las primitivas partidas de «maquis» desplegadas en España durante la Segunda Guerra Mundial y constituidas por antiguos combatientes republicanos que trataban de derrocar, por la fuerza de las armas, el régimen establecido al finalizar la guerra civil.

En este campo, la información tenía su marco principal dentro de la "contrapartida", nombre con el que eran conocidas las unidades del Servicio de Información («Grupos de Información») y que obtuvieron resultados altamente positivos.

La Instrucción General número 5, de 12 de julio de 1950, trata de resaltar, aún más, la importancia del SIGC y darle un mayor impulso, debido a la extraordinaria necesidad que se sentía en la lucha contra el bandolerismo, originando una nueva organización del mismo. 
Pero quizá el paso más importante para la normalización de la actuación del SIGC puede definirse con la publicación, en 1958, de las «Normas para la Organización y Funcionamiento del Servicio de Información", por las cuales ha de regirse el SIGC.

En estas Normas se refundieron más de un centenar de Órdenes e Instrucciones Generales y Particulares y, sin cambiar fundamentalmente su contenido, se concretaron y flexibilizaron muchos puntos.

En 1965, la Dirección General de la Guardia Civil (2a Sección de Estado Mayor) publica unas nuevas «Normas para la organización y funcionamiento del Servicio de Información».

La primera de las misiones que se le asignaba era, literalmente, «Informar a los Mandos respectivos de todo lo que ocurra en su demarcación, en relación con noticias y situaciones de carácter general, militar, político-social, tráfico y particulares del Cuerpo».

En estas normas se enfatiza, una vez más, que «todo el personal que constituye el Cuerpo de la Guardia Civil o esté afecto al mismo, cualquiera que sea su categoría, deberá considerarse como agente del Servicio y formará parte de los órganos de investigación de su Unidadı.

Precisamente, la Central del Servicio, que era un negociado de la $2^{a}$ Sección de Estado Mayor, constituía el órgano responsable de enlazar con los Servicios de Información de otros Organismos a nivel nacional. Los enlaces que deberían establecerse de forma más continuada eran con:

- Alto Estado Mayor, en lo que se refería a pasos clandestinos, noticias procedentes del exterior, personal de las Bases americanas, espionaje, sabotaje, conflictos sociales, etc.

- $2^{a}$ Sección Bis del Estado Mayor Central, en lo que atañía a información militar exterior, actividades de personal perteneciente al Ejército, noticias relacionadas con las Unidades del Ejército de Tierra y aquellas otras que pudieran ser interpretadas torcidamente en el exterior.

- $2^{a}$ Sección Bis del Estado Mayor del Aire, en lo relacionado con vuelos sospechosos, accidentes aéreos, noticias relacionadas con las Bases Aéreas y actividades del personal de Aviación, etc.

- $2^{a}$ Sección del Estado Mayor de la Armada, en lo que se refería a noticias relacionadas con las Bases Navales, personal de Marina y movimientos de buques, lanchas dedicadas al contrabando, incidentes en los puertos, comportamiento de tripulantes, etc. 
Asimismo se definieron las relaciones que habían de mantenerse con el Ministerio de la Gobernación, Dirección General de Seguridad, Ministerio de Información y Turismo, Servicio de Información del Movimiento y otras Jefaturas y Oficinas.

Las citadas Normas establecían minuciosamente las plantillas de los «SIGC,s de Zonas, Tercios y Comandancias», descendiendo hasta señalar, incluso, las plantillas de los Grupos de Información y de algunos Puestos del extrarradio de Madrid. En total, el personal dedicado a información quedaba fijado en 104 Comandantes, 3 Oficiales, 6 Brigadas, 77 Sargentos, 128 Cabos y 735 Guardias, lo que significaba un total de 1.033 personas.

Este potencial humano constituyó, sin duda alguna, el principal factor para que el SIGC obtuviera los significativos éxitos que siempre le ha caracterizado.

\section{Bibliografia}

Bertrán y Musitu, J. (1940): Experiencias de los Servicios de Información del Nordeste de España (S.I.F.NE) durante la guerra. Espasa-Calpe, Madrid.

BOE $\mathrm{n}^{\circ} 274$ de 1 de octubre de 1939.

BOE $\mathrm{n}^{\circ} 321$ de 17 de noviembre de 1939

BOE $n^{\circ} 243$. Septiembre de 1939.

BOE $\mathrm{n}^{\circ} 77$ de 17 de marzo de 1940.

BOE $\mathrm{n}^{\circ} 60$ de 10 de marzo de 1972 .

BOE $n^{\circ} 68$ de 20 de marzo de 1972.

CANIS MatuTEs, L. (1947): La Organización Informativa y el Agente Secreto, Madrid, [s.n.]. CORES, A. (1940): "El Servicio de Información”, Ejército, n. ${ }^{\circ} 9$.

DíAz, A. (2000): «The Spanish Intelligence Services: An Overview»., Paper for the Political Sciences Association - UK 50th Annual Conference, 10-13 April 2000, Landon(disponible en Internet: www.psa.ac.uk/cps/2000/Diaz\%20Antonio.pdf. Consultado el $1 / 12 / 2004)$.

Díaz CARmona, A. (1963): La Información y la Seguridad del Estado. Madrid.

DOME n ${ }^{\circ} 38$, de 16 de noviembre de 1939.

DiRECCIÓN GENERAL DE LA GUARDIA CIVIL (1965): Normas para la organización y funcionamiento del Servicio de Información.

M. GutiéRrez MELlado, (1983). Un soladado de España (Conversaciones con Jesús Picatoste), Barcelona, Argos Vergara.

Medina F. (1995): Las sombras del poder. Los Servicios Secretos de Carrero a Roldán. Espasa Calpe, Madrid.

Puell de la VILla, F. (1997): Gutiérrez Mellado Un militar del siglo XX. Colección Biblioteca Nueva, Madrid.

Quero Rodiles, F. (2004): Paz y Seguridad. La razón y la fuerza. Colección Adalid, Madrid.

San Martín J.I. (1983): Servicio Especial. A las órdenes de Carrero Blanco. Barcelona, Editorial Planeta.

Sun Tzu: El Arte de la Guerra. Madrid, Ed. Fundamentos, 1970.

Valle Almazan, R. (1970): El Servicio de Información de la Guardia Civil. Revista de Estudios Históricos de la Guardia Civil, $n^{\circ} 6$. 